\section{(A) OPEN ACCESS}

\author{
${ }^{1}$ The Royal Free Sheila Sherlock \\ Liver Centre, Royal Free \\ Hospital and UCL Institute of \\ Liver and Digestive Health, \\ London, UK \\ ${ }^{2}$ Department of \\ Histopathology, Royal Free \\ Hospital, London, UK \\ ${ }^{3}$ Transplant Unit, Royal \\ Infirmary of Edinburgh, \\ Edinburgh, UK \\ ${ }^{4}$ Liver Unit, St Vincent's \\ University Hospital, Dublin \\ Ireland
}

Correspondence to Professor Andrew K Burroughs, The Royal Free Sheila Sherlock Liver Centre and University Department of Surgery, UCL and Royal Free Hospital, Pond Street, Hampstead, London NW3 2QG, UK

Andrew.Burroughs@nhs.net

Received 9 July 2013

Revised 6 September 2013 Accepted 25 September 2013

Published Online First

16 October 2013

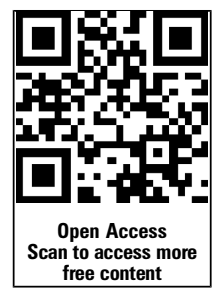

To cite: Manousou $P$, Cholongitas E, Samonakis D, et al. Gut 2014:63: 1005-1013.

\title{
Reduced fibrosis in recurrent HCV with tacrolimus, azathioprine and steroids versus tacrolimus: randomised trial long term outcomes
}

\author{
Pinelopi Manousou, ${ }^{1}$ Evangelos Cholongitas, ${ }^{1}$ Dimitrios Samonakis, ${ }^{1}$ \\ Emmanuel Tsochatzis, ${ }^{1}$ Alice Corbani, ${ }^{1}$ A P Dhillon, ${ }^{2}$ Janice Davidson, ${ }^{3}$ \\ Manuel Rodríguez-Perálvarez, ${ }^{1}$ D Patch, ${ }^{1}$ J O'Beirne, ${ }^{1}$ D Thorburn, ${ }^{1}$ TuVinh Luong, ${ }^{2}$ \\ K Rolles, ${ }^{1}$ Brian Davidson, ${ }^{1}$ P A McCormick, ${ }^{4}$ Peter Hayes, ${ }^{3}$ Andrew K Burroughs ${ }^{1}$
}

\section{ABSTRACT}

Objective Early results of a randomised trial showed reduced fibrosis due to recurrent HCV hepatitis with tacrolimus triple therapy (TT) versus monotherapy (MT) following transplantation for HCV cirrhosis. We evaluated the clinical outcomes after a median 8 years of followup, including differences in fibrosis assessed by collagen proportionate area (CPA).

Design 103 consecutive liver transplant recipients with HCV cirrhosis receiving cadaveric grafts were randomised to tacrolimus MT ( $n=54)$ or TT $(n=49)$ with daily tacrolimus ( $0.1 \mathrm{mg} / \mathrm{kg}$ divided dose), azathioprine $(1 \mathrm{mg} / \mathrm{kg})$ and prednisolone $(20 \mathrm{mg})$, the last tailing off to zero by 6 months. Both groups had serial transjugular biopsies with hepatic venous pressure gradient (HVPG) measurement. Time to reach Ishak stage 4 was the predetermined endpoint. CPA was measured in all biopsies. Factors associated with HCV recurrence were evaluated. Clinical decompensation was the first occurrence of ascites/hydrothorax, variceal bleeding or encephalopathy.

Results No significant preoperative, peri-operative or postoperative differences between groups were found. During 96 months median follow-up, stage 4 fibrosis was reached in 19 MT/11 TT with slower fibrosis progression in TT $(p=0.009)$. CPA at last biopsy was $12 \%$ in MT and $8 \%$ in TT patients ( $p=0.004)$. $14 \mathrm{MT} /$ three TT patients reached HVPG $\geq 10 \mathrm{~mm} \mathrm{Hg}(p=0.002)$; $10 \mathrm{MT} /$ three TT patients, decompensated. Multivariately, allocated MT ( $p=0.047$, OR $3.23,95 \% \mathrm{Cl} 1.01$ to 10.3 ) was independently associated with decompensation: 14 MT/ seven TT died, and five MT/ four TT were retransplanted.

Conclusions Long term immunosuppression with tacrolimus, azathioprine and short term prednisolone in $\mathrm{HCV}$ cirrhosis recipients resulted in slower progression to severe fibrosis assessed by Ishak stage and CPA, less portal hypertension and decompensation, compared with tacrolimus alone.

ISRCTN94834276—-Randomised study for immunosuppression regimen in liver transplantation.

\section{INTRODUCTION}

We published early results of a randomised trial in liver transplant recipients with HCV cirrhosis assessing tacrolimus monotherapy (MT) versus tacrolimus, azathioprine and prednisolone triple therapy

\section{Significance of this study}

What is already known on this subject?

- Immunosuppression worsens severity of recurrence of HCV after liver transplantation.

- There are very few studies and only one randomised study assessing immunosuppressive protocols on different severity of recurrence of chronic HCV hepatitis.

What are the new findings?

- Triple therapy with tacrolimus, azathioprine and tapering steroids resulted in less fibrosis progression compared with tacrolimus monotherapy, contrary to the initial hypothesis, that less immunosuppression should reduce progression of HCV recurrent disease.

- Triple therapy also resulted in less progression of clinically significant portal hypertension (hepatic venous pressure gradient $\geq 10 \mathrm{~mm} \mathrm{Hg}$ ) and less clinical decompensating events (ascites, bleeding, varices, encephalopathy).

- Discontinuation of azathioprine resulted in further fibrosis progression compared with continuation of azathioprine.

- The fibrosis progression with triple therapy is the lowest recorded in the literature.

How might it impact on clinical practice in the foreseeable future?

- This trial obliges a review of immunosuppressive protocols in patients transplanted with HCV cirrhosis. The use of azathioprine should be considered.

- Azathioprine and other immunosuppressive agents need to be tested in HCV replicon systems to assess if there is a direct antiviral effect and in cell systems for any potential immunological interaction with profibrotic and antifibrotic mechanisms. 
contrary to the starting hypothesis that the lesser immunopotency with MT should result in less fibrosis.

However, despite our initial trial results and other consistent data with more patients, ${ }^{2-4}$ including a possible benefit with azathioprine, ${ }^{5}$ the optimal immunosuppression for HCV transplant recipients is still debated. ${ }^{6}$ Indeed, immunosuppression worsens the severity of $\mathrm{HCV}$ recurrence. ${ }^{6}$ Cyclosporine has no advantage versus tacrolimus regarding stage progression ${ }^{7}$ despite in vitro (but not in vivo) activity against $\mathrm{HCV}^{8}$ Tacrolimus compared with cyclosporine improves both patient and graft survival including patients transplanted for hepatitis C cirrhosis ${ }^{6}$ and is the preferred calcineurin inhibitor.

Therefore, we evaluated outcomes in our trial, after a median of 8 years of follow-up, including the original end points as well as differences in hepatic venous pressure gradient (HVPG) and collagen proportionate area (CPA) as a quantitative measure of fibrosis and clinical decompensation.

\section{PATIENTS AND METHODS}

Inclusion-exclusion criteria, randomisation and endpoints

From January 2000 to June 2007, at the Royal Free Hospital, consecutive transplant recipients were randomised if they had cirrhosis, were HCV RNA positive in serum and previous histology was compatible with HCV liver disease. Randomisation at the Royal Edinburgh Infirmary and St Vincent's University Hospital was between 12/2003 and 5/2006. Inclusion and exclusion criteria were published previously. ${ }^{1}$ The study protocol was approved by the Hospital Ethics committees at each site.

Follow-up stopped at death, retransplantation or $1 / 2013$. We analysed the original primary endpoints-progression to Ishak stage 4 and graft failure either resulting in retransplantation or patient's death. We also evaluated patients' survival, acute cellular rejection episodes, chronic rejection, recurrence of HCV (defined by Ishak inflammation score $\geq 4$ ), HVPG progression to $10 \mathrm{~mm} \mathrm{Hg}$, CPA, fibrosis progression assessed by CPA and Ishak stage (for comparison with other published studies), and time to first episode of clinical decompensation defined as whichever occurred first, of ascites/hydrothorax, variceal bleeding or encephalopathy.

For each patient, the following were evaluated: demographic and clinical data (including concomitant hepatocellular carcinoma (HCC) and/or alcoholic aetiology), donor age/gender, cold/ warm ischaemia time, initial immunosuppression and subsequent changes, occurrence and treatment of rejection episodes, cytomegalovirus or other infections, histological episodes of de novo hepatitis, genotype, viral load pre-LT and 1 year post-liver transplantation (LT), antiviral treatment and sustained virological response (SVR), diabetes mellitus pretransplant and posttransplant, human leucocyte antigen and blood group compatibility of donor/recipient, sex match/mismatch and tacrolimus levels at 5, 15 and 30 days post-LT.

\section{Immunosuppression regimens}

The MT group received tacrolimus $0.1 \mathrm{mg} / \mathrm{kg} / \mathrm{day}$ (two divided doses). The TT group received the same tacrolimus dosing, together with azathioprine-initially intravenously then orally$1 \mathrm{mg} / \mathrm{kg} / \mathrm{day}$, and methylprednisolone (16 mg/day intravenous) until oral intake was established $(20 \mathrm{mg} /$ day prednisolone $)$. Tacrolimus trough concentrations were evaluated on alternate week days. The doses were adjusted to maintain a whole blood level within 5-14 ng/mL (aiming for 5-10). Azathioprine was continued at the same starting dose unless neutropenia developed: 16 patients discontinued azathioprine between 10 and 37 months (median 14 months) post-LT. Prednisolone was gradually tapered from 3 weeks onwards and then stopped between
3 and 6 months, according to each centre's practice. Protocol biopsies were undertaken to diagnose acute cellular rejection between days 5 and 10. If moderate or severe rejection was diagnosed, daily intravenous $1 \mathrm{gm}$ methylprednisolone was given for 3 days. $^{9}$

\section{Virological assays}

Determination of HCV genotype was performed by reverse transcription PCR and reverse hybridisation assay of the amplified sequence (InnoLipa HCV II, Innogenetics, Zwijnaarde, Belgium). ${ }^{10}$

Qualitative tests were performed by a reverse transcription PCR assay (Amplicor HCV, Roche Diagnostic Systems Inc, Branchburg, New Jersey, USA-later Bayer Thermomechanical Analyzer Component system, Berkeley, California, USA). ${ }^{11}$

\section{Liver biopsies}

Protocol liver biopsies were performed at yearly intervals and also if clinically indicated. All liver biopsies were reviewed by liver trained histopathologists in each centre, in a blinded fashion.

Liver biopsy samples were formalin fixed, paraffin embedded and stained with H\&E, Gordon and Sweet staining was used for reticulin and Sirius red and Van Gieson stains were used in Edinburgh. All biopsies at the Royal Free Hospital were restained with picroSirius Red to ensure comparable staining for collagen quantification and determination of CPA by digital image analysis. The stage of disease (fibrosis 0-6) and the grade of necroinflammatory activity were evaluated according to Ishak et al. ${ }^{12}$

The number of liver cores, length of biopsy (lengths of each core summed), and portal tract number per core and in total were recorded. ${ }^{13}$ Liver biopsies $<12 \mathrm{~mm}$ long were excluded (29 of 310). Complete portal tracts were defined according to Crawford and colleagues. ${ }^{14}$ The equipment used and CPA measurement were performed as previously described. ${ }^{15}$

Acute cellular rejection was graded using the Royal Free Hospital score. ${ }^{16}$ Histological de novo hepatitis (HDNH) C termed 'histological acute hepatitis $C^{\text {' }}$ previously ${ }^{12}$ was defined as before as an increase in alanine aminotransferase levels ( $>2$ upper normal limit), together with histological changes consistent with hepatitis without diagnostic features of cellular rejection, duct loss or other cause of liver injury, including alloimmune hepatitis (autoantibodies negative). ${ }^{2}$

Fibrosis progression in each patient was calculated by percentage change of fibrosis according to CPA (CPA in latest biopsy subtracted from CPA at 1 year post-LT, divided by time in years between the two biopsies: CPA\%/year). Ishak stage progression was calculated as in latest biopsy subtracted from stage in the biopsy at 1 year, divided by time in years-stage 'units'/year between the two biopsies.

\section{Statistical analysis}

Results are expressed as median and ranges. Categorical variables were compared using the $\chi^{2}$ or Fisher's exact tests. Continuous variables were compared by Student $t$ test, or if not normally distributed by the Mann-Whitney test. We compared the two randomised groups for histological, virological and clinical outcomes in a preplanned evaluation.

Statistical comparison was made by life tables (Kaplan-Meier) and $\log$ rank testing. All the following variables associated with HCV recurrence in the literature (table 1) - except IL28B-were evaluated in the Cox regression analysis: donor age/gender, cold/ warm ischaemia time, initial and changes in immunosuppression 
Table 1 Variables evaluated in the univariate analysis for the different endpoints examined

\begin{tabular}{|c|c|c|c|c|c|c|c|}
\hline & MT & TT & $\begin{array}{l}\text { Stage } 4 \\
\mathrm{p} \text { Value }\end{array}$ & $\mathrm{CPA} \geq 6 \%$ & $\mathrm{CPA} \geq 7.2 \%$ & $\mathrm{HVPG} \geq 10 \mathrm{~mm} \mathrm{Hg}$ & Decompensation \\
\hline Cold/warm ischaemia time (min) & $680 / 46$ & $688 / 41$ & NS & NS & NS & NS & NS \\
\hline Treatment allocation (evaluated) & $54(49)$ & $49(48)$ & $<0.001$ & $<0.001$ & $<0.001$ & $<0.001$ & $<0.001$ \\
\hline Stopped azathioprine & NA & $16(33 \%)$ & $<0.001$ & $<0.001$ & $<0.001$ & 0.012 & 0.013 \\
\hline \multicolumn{8}{|c|}{ Tacrolimus trough concentrations ( $\mathrm{ng} / \mathrm{mL})$} \\
\hline 5 days & 7.7 & 5 & 0.002 & 0.002 & 0.01 & 0.017 & 0.01 \\
\hline 15 days* & 8.5 & 6.1 & 0.003 & 0.001 & 0.01 & 0.001 & 0.01 \\
\hline 30 days* & 7.9 & 6.7 & 0.01 & 0.01 & 0.04 & 0.02 & 0.01 \\
\hline Conc. HCC & 17 & 13 & NS & NS & NS & NS & 0.03 \\
\hline Conc. ALD & 10 & 12 & NS & NS & NS & NS & NS \\
\hline Age & 48.9 years & 50 years & NS & NS & NS & NS & NS \\
\hline Donor age & 48.5 years & 44 years & 0.01 & 0.01 & 0.01 & 0.04 & 0.02 \\
\hline Gender mismatch & 17 & 17 & NS & NS & NS & NS & NS \\
\hline Rejection episodes & 42 & 64 & 0.002 & 0.0033 & 0.04 & 0.033 & NS \\
\hline Rejection treatment (courses) & 21 & 30 & 0.002 & 0.01 & 0.03 & 0.038 & NS \\
\hline $\mathrm{HDNH}$ & 17 & 8 & $<0.001$ & $<0.001$ & $<0.001$ & $<0.001$ & $<0.001$ \\
\hline $\mathrm{CMV}$ viraemia treated & 7 & 10 & NS & NS & NS & NS & NS \\
\hline \multicolumn{8}{|l|}{ Viral load loglU/mL (median) } \\
\hline Pre-LT & 5.29 & 5.36 & NS & NS & NS & NS & NS \\
\hline $3 \mathrm{~m}$ post-LT & 6.6 & 6.39 & NS & NS & NS & NS & NS \\
\hline Genotype 1/1b & $41 \%$ & $41 \%$ & NS & NS & NS & NS & NS \\
\hline Antiviral treatment & 19 & 11 & 0.01 & 0.01 & 0.01 & 0.001 & 0.001 \\
\hline SVR & 3 & 3 & NS & NA & NA & NA & NA \\
\hline \multicolumn{8}{|l|}{ DM } \\
\hline Pre-LT & 13 & 13 & NS & NS & NS & NS & NS \\
\hline Post-LT (last follow-up) & 19 & 15 & 0.013 & 0.038 & 0.044 & NS & NS \\
\hline
\end{tabular}

${ }^{*}$ Median trough levels derived from all measurements up to days 15 and 30 post-LT.

ALD, alcoholic liver disease; CMV, cytomegalovirus; CPA, collagen proportionate area; DM, diabetes mellitus; HCC, hepatocellular carcinoma; HDNH, histological de novo hepatitis; HVPG, hepatic venous pressure gradient; LT, liver transplantation; MT, monotherapy; NA, non-applicable; NS, non-significant; SVR, sustained virological response; TT, triple therapy.

occurrence and treatment of rejection episodes, cytomegalovirus or other infection, HDNH episodes, genotype, viral load pre-LT and 1 year post-LT, antiviral treatment and SVR, diabetes mellitus pre-LT and post-LT, human leucocyte antigen and blood group compatibility of donor/recipient, sex match/mismatch and tacrolimus levels at $5 / 15 / 30$ days post-LT.

A $\mathrm{p}$ value $<0.05$ was considered statistically significant. SPSS V.20.0 was used.

Patients were censored at the time of SVR, when analysing progression to HVPG $\geq 10 \mathrm{~mm} \mathrm{Hg}$, to CPA cut-offs of $6 \%$ and $7.2 \%$, to first clinical decompensation event, and survival. As reported previously, sample size was calculated to be 110 patients: S4 was estimated to occur in $35 \%$ by 3 years with a projected decrease to $10 \%$ with tacrolimus MT, and this required a sample size of 99 . Considering a dropout rate of $10 \%$ (including early deaths), we concluded that 110 patients would be needed with a two-tailed test with significance at 5\% and a power of $80 \%(1-\mathrm{B}) .{ }^{17}$

\section{RESULTS}

\section{Patients' demographic and transplant data}

A total of 103 patients (89 Royal Free Hospital, eight Royal Edinburgh Infirmary and six St Vincent's Hospital) were randomised as previously documented: ${ }^{1} 29$ women, 74 men; 30 had HCC and 22 concomitant alcoholic liver injury. In the last follow-up, there were only two alcohol relapsers, one in each randomised arm. Two patients were coinfected with hepatitis B or $\mathrm{D}$ virus (remained HBV-DNA negative in blood throughout the study).
By randomisation, 54 received MT and 49 TT. The groups were well matched at randomisation with no significant differences in preoperative, peri-operative or immediately postoperative variables: four were retransplanted early post-LT, two for hepatic artery thrombosis and one for primary non-function in the MT group; and one TT for hepatic artery thrombosis. Two MT patients were withdrawn within the first month post-LT because of side effects of treatment.

We analysed the remaining 97: 49 MT and 48 TT. Median follow-up was 96 months (range 1-146): 91.6 months MT and 98.7 months TT; $15 / 97$ (15.5\%) died within 3 years from randomisation. In all, 78/97 (80\%) had a follow-up of more than 3 years, fulfilling the sample size calculation based on Log rank testing.

Clinical characteristics were well balanced and HCV genotypes were similarly distributed. In tacrolimus MT: 20 patients genotype 1 (41\%), seven genotype 2 (14\%), 16 genotype 3 (33\%) and six genotype 4 (12\%). In TT group, the distribution was 20 patients genotype 1 (41\%), one genotype 2 (2\%), 19 genotype $3(40 \%)$, seven genotype $4(15 \%)$ and genotype $5(2 \%)$.

Median HCV RNA levels were not significantly different, pretransplant or at 1 or 3 months post-LT. ${ }^{1}$ Antiviral treatment for HCV recurrence was used in 25 of 30 patients reaching stage 4 (19 MT, 11 TT), with six achieving SVR (18, 36 and 52 months MT; 36, 38 and 40 months TT). The median time to initiate therapy was the same in the two trial arms: 45 months for 19 MT patients and 51 months for 11 TT patients. All patients were treated with pegylated interferon $\alpha-2 b \quad 0.5 \mu \mathrm{g} / \mathrm{kg}$ weekly escalating to $1 \mu \mathrm{g} / \mathrm{kg}$, and ribavirin $200 \mathrm{mg}$ escalating to 
$800 \mathrm{mg} /$ daily. The HDNH episodes were only diagnosed within 6 months post-LT, and occurred in 17 MT and eight TT patients.

Tacrolimus trough levels were a median of $7.7 \mathrm{ng} / \mathrm{mL}$ (MT) and $5 \mathrm{ng} / \mathrm{mL}(\mathrm{TT})(\mathrm{p}=0.03)$ at 5 days; $8.5 \mathrm{ng} / \mathrm{mL}(\mathrm{MT})$ and $6.1 \mathrm{ng} / \mathrm{mL}(\mathrm{TT})(\mathrm{p}=0.017)$ at 15 days post-LT; and $7.9 \mathrm{ng} / \mathrm{mL}$ $(\mathrm{MT})$ and $6.7 \mathrm{ng} / \mathrm{mL}(\mathrm{TT})(\mathrm{p}=0.031)$ at 30 days post-LT. The difference in median tacrolimus levels was maintained up to 6 months post-LT: $7 \mathrm{ng} / \mathrm{mL}$ in MT group versus $5.8 \mathrm{ng} / \mathrm{mL}$ in TT arm $(p=0.044)$. There was no difference at 1 year post-LT. The median tacrolimus levels at 1 year post-LT were not significantly different between those who discontinued azathioprine before 1 year post-LT $(7.7 \mathrm{ng} / \mathrm{mL})$ versus those who were still on azathioprine at that point $(6.7 \mathrm{ng} / \mathrm{mL})$.

There were no new rejection episodes compared with those previously published: ${ }^{19}$ During the first 3 months, 22 MT had 42 rejection episodes and 16 received 21 courses of methylprednisolone. In comparison, 31 TT had 64 rejection episodes and 24 received 30 courses of methylprednisolone. It should be noted that after the last bolus, steroid dosage (if in TT arm) reverted to $20 \mathrm{mg} / \mathrm{day}$ (ie, no high to low tail off of oral steroids) or none in MT arm.

The proportion of patients whose serum creatine rose to $\geq 130 \mu \mathrm{mol} / \mathrm{L}(1.5 \mathrm{mg} / \mathrm{dL})$ during the first 3 months posttransplant was similar: $23 \%$ MT versus 20\% TT. At the last follow-up, abnormal serum creatine $(>1.5 \mathrm{mg} / \mathrm{dL})$ was noted in nine out of 37 (24\%) patients alive in the MT and five out of 41 (12\%) patients alive in TT group. No patient has ended up on dialysis. Incidence of diabetes post-LT was 33\% MT and 31\% TT.

There was no difference in numbers of biopsies and average number of biopsies/patient performed between groups. Patients' characteristics are shown in table 2. The number of patients with suitable biopsies evaluated for Ishak staging was 90/97 (45 MT/45 TT) and for CPA was 81/89 Royal Free patients (37 MT/44 TT).

\section{Factors associated with reaching Ishak stage 4 or greater}

At least stage 4 was reached by 19 MT patients at a median of 32 months: eight reached stage 4 , eight stage 5 and three stage 6. Correspondingly, 11 TT patients reached stage 4 or greater at a median of 49 months (six reached stage 5, none stage 6). Patients receiving antiviral treatment or achieving SVR were not censored as treatment in all patients was initiated after reaching Ishak stage 4 or greater. In univariate and multivariate analyses, three factors were associated with fibrosis stage $\geq 4$ : randomisation to allocated MT treatment $(p=0.001$, OR 2.94, 95\% CI 1.3 to 6.7 ), HDNH ( $p=0.015$, OR $2.67,95 \%$ CI 1.23 to 5.8 ) and discontinuation of azathioprine $(\mathrm{p}=0.036$, OR $2.24,95 \%$ CI 1.3 to 3.9). Patients who died without reaching stage 4 (four MT, one TT) were censored at the last biopsy with its Ishak stage. Hazard curves of MT/TT allocation ( $p=0.005$ MantelCox $)$ and use/discontinuation of azathioprine $(p=0.003$ Mantel-Cox) are shown in figure 1 .

\section{Factors associated with CPA cut-offs}

As previously published, CPA of $6 \%$ at 1 year biopsy post-LT was highly predictive of clinical outcome in a larger recurrent $\mathrm{HCV}$ population after liver transplantation ${ }^{3}$ and CPA of $7.2 \%$ was independently associated with portal hypertension, that is, HVPG $\geq 6 \mathrm{~mm} \mathrm{Hg}$. ${ }^{15}$ We used the cut-off of $6 \%$ of CPA and the time to first reach $\mathrm{CPA} \geq 6 \%$ to compare the allocated treatments, including a multivariate analysis: 20 MT patients reached $\mathrm{CPA} \geq 6 \%(20 / 37$ or $54 \%)$ at a median of 41 months,
Table 2 Characteristics of patients transplanted for HCV cirrhosis randomised to either tacrolimus monotherapy or triple therapy (tacrolimus, prednisolone and azathioprine)

\begin{tabular}{|c|c|c|}
\hline & $\begin{array}{l}\text { Monotherapy } \\
49\end{array}$ & $\begin{array}{l}\text { Triple therapy } \\
48\end{array}$ \\
\hline \multicolumn{3}{|c|}{ Follow-up (median) } \\
\hline $96(1-146) \mathrm{m}$ & 91.6 & 98.7 \\
\hline \multicolumn{3}{|c|}{ Biopsies performed } \\
\hline Years $1 / 2$ & $34 / 27$ & $40 / 30$ \\
\hline Years $3 / 4$ & $26 / 17$ & $27 / 19$ \\
\hline Years $5 / 6$ & $18 / 14$ & $16 / 13$ \\
\hline Years $7 / 8$ & $11 / 9$ & $10 / 9$ \\
\hline Years $9 / 10$ & $2 / 3$ & $2 / 2$ \\
\hline Biopsy index* & 3.31 & 3.48 \\
\hline \multicolumn{3}{|c|}{ Reaching Ishak stage 4} \\
\hline $\mathrm{N}$ & 19 & 11 \\
\hline Median & $32 \mathrm{~m}$ & $49 \mathrm{~m}$ \\
\hline \multicolumn{3}{|l|}{ Reaching $C P A \geq 6 \%$} \\
\hline N & $20 / 33(61 \%)$ & $13 / 39(33 \%)$ \\
\hline Median & $41 \mathrm{~m}$ & $49 m$ \\
\hline \multicolumn{3}{|c|}{ Reaching CPA $\geq 7.2 \%$} \\
\hline $\mathrm{N}$ & $21 / 33$ & $14 / 39$ \\
\hline Median & $42 \mathrm{~m}$ & $51 \mathrm{~m}$ \\
\hline \multicolumn{3}{|c|}{ Reaching $\mathrm{HVPG} \geq 10 \mathrm{~mm} \mathrm{Hg}$} \\
\hline $\mathrm{N}$ & $11 / 33$ & $4 / 31$ \\
\hline \multicolumn{3}{|l|}{ Decompensated } \\
\hline $\mathrm{n}$ (months) & 9 (70 months) & 4 (91 months) \\
\hline \multicolumn{3}{|l|}{ Deaths } \\
\hline $\mathrm{n}$ & 14 & 7 \\
\hline
\end{tabular}

while 13 TT reached $\mathrm{CPA} \geq 6 \%(13 / 44,30 \%)$ at a median of 49 months. In the multivariate analysis, allocated treatment with MT ( $p=0.007$, OR $2.67,95 \%$ CI 1.31 to 5.46) and HDNH $(\mathrm{p}=0.001$, OR $3.27,95 \%$ CI 1.61 to 6.6 ) were independently associated with $\mathrm{CPA} \geq 6 \%$. For $\mathrm{CPA} \geq 7.2 \%$, allocated MT treatment $(p=0.004$, OR $2.85,95 \%$ CI 1.38 to 5.86$)$, HDNH $(\mathrm{p}=0.006$, OR $2.69,95 \%$ CI 1.32 to 5.48$)$ and discontinuation of azathioprine $(p=0.011$, OR $2.1,95 \%$ CI 1.1 to 2.8$)$ were independent factors. Hazard curves are shown in figure 2 for CPA cut-offs of $6 \%$ and 7.2\% $(p=0.002$ and $p=0.001$ MantelCox respectively).

\section{Factors associated with portal hypertension}

HVPG measurement was performed combined with transjugular biopsies in $33 \mathrm{MT}$ and $31 \mathrm{TT}$ patients. These represent 78\% MT and 72\% TT patients surviving at 1 year at the Royal Free Hospital as HVPG was not measured in Edinburgh or Dublin. There were 154 HVPG measurements post-LT: 64 at a median of 17 months, 41 at a median of $31 \mathrm{~m}, 30$ at a median of $48 \mathrm{~m}$, 15 at a median of $63 \mathrm{~m}$ and four at a median of $86 \mathrm{~m}$. $\mathrm{HVPG} \geq 10 \mathrm{~mm} \mathrm{Hg}$ (clinically significant portal hypertension) was reached in $11 \mathrm{MT}$ compared with four TT patients. Cox regression analysis revealed $\mathrm{HDNH}(\mathrm{p}=0.015$, OR $3.68,95 \%$ CI 1.26 to 10.69$)$ and allocated MT treatment $(p=0.017$, OR $4.13,95 \%$ CI 1.28 to 13.29 ) to be independently associated with $\mathrm{HVPG} \geq 10 \mathrm{~mm} \mathrm{Hg}$ : hazard curves are shown in figure 3 ( $p=0.027$ Mantel-Cox and 0.019 Breslow). 


\section{Hazard curves of reaching stage 4}

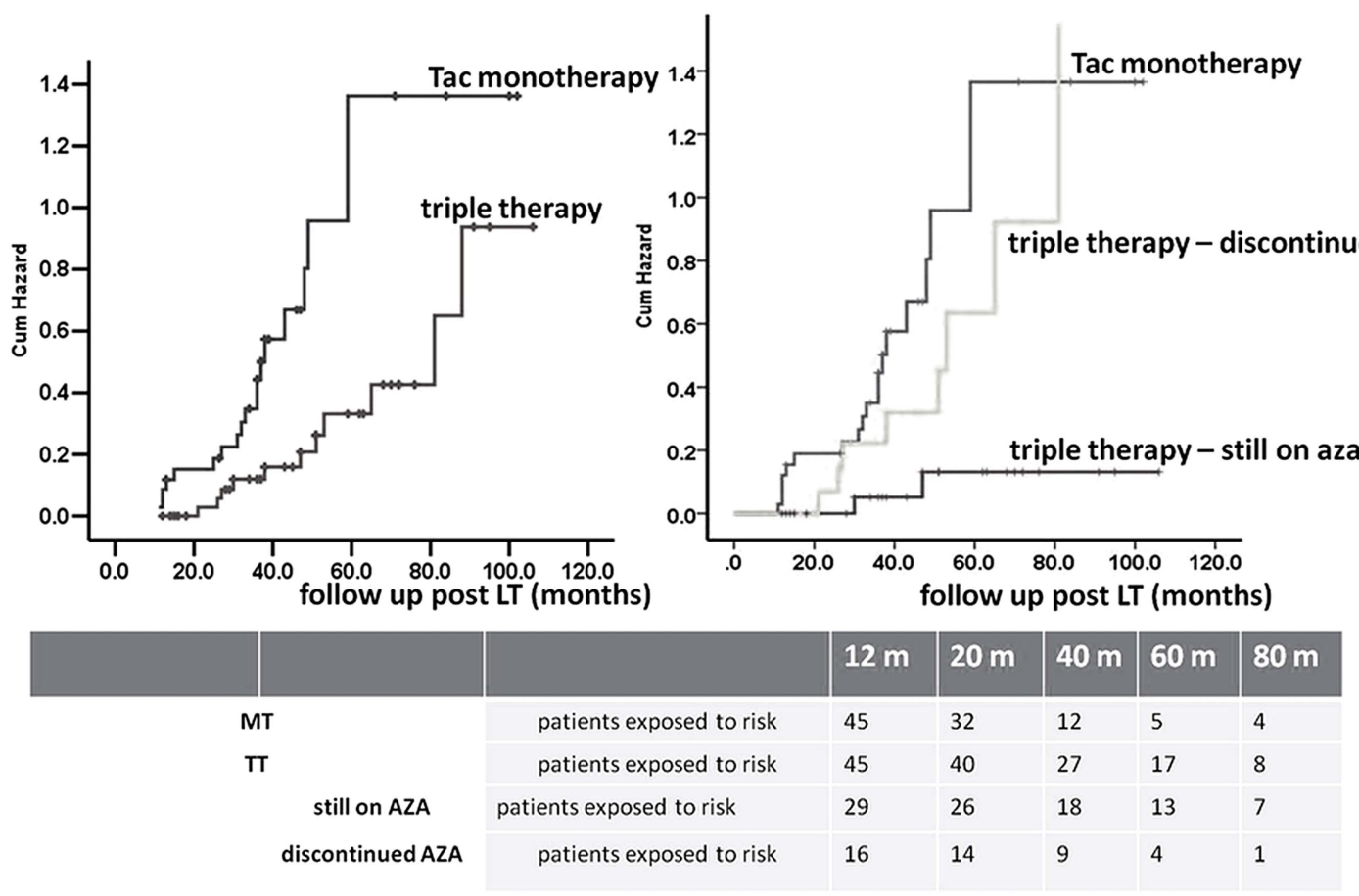

Figure 1 Hazard curves of Ishak stage 4. Hazard curves of reaching Ishak stage 4 in the two treatment arms ( $p=0.005$ Mantel-Cox). In all, 19 MT patients reached stage $\geq 4$ at a median of 32 months, while 11 TT reached stage $\geq 4$ at a median of 49 months post-LT. Sixteen patients discontinued azathioprine between 10 and 37 months post-LT. MT, monotherapy; TT, triple therapy.

\section{Factors associated with clinical decompensation}

Decompensation occurred in 13 patients (all reached stage 5/6 at the time of decompensation) at a mean of 82 months: nine MT patients (seven ascites, one variceal bleeding, one encephalopathy) at a mean of $70 \mathrm{~m}$ and four TT patients (three ascites, one encephalopathy) at a mean time of $91 \mathrm{~m}$. Hazard curves are shown in figure 3 ( $\mathrm{p}=0.015$ by Mantel-Cox, 0.037 Breslow).

In the Cox regression analysis, allocated MT treatment was the only statistically significant factor associated with clinical decompensation ( $p=0.047$, OR $3.23,95 \%$ CI 1.01 to 10.3 ).

\section{Fibrosis progression rate}

We evaluated 310 biopsies for Ishak stage and 289 biopsies for CPA due to inadequate material for restaining. The number of biopsies performed every year were: 74 in year 1 (34 MT/40 TT), 57 in year 2 (27 MT/30 TT), 53 in year 3 (26 MT/27 TT), 36 in year 4 (17 MT/19 TT), 34 in year 5, (18 MT/16 TT), 27 in year 6 (14 MT/13 TT), 21 in year 7 (11 MT/10 TT), 18 in year 8 (9 MT/9 TT), 4 in year $9(2 \mathrm{MT} / 2 \mathrm{TT})$ and 5 in year 10 (3 MT/2 TT). Fibrosis progression according to CPA and stage progression over time are shown in figure 4. Median CPA fibrosis progression rate was $0.7 \%$ year $(0.74 \% /$ year MT, $0.67 \%$ year TT). Mean stages per year (given for comparison with published studies) were: at 1 year $(1.45), 2$ years $(2.1), 3$ years $(2.38)$, 4 years (2.86), 5 years (3), 6 years (3.2), 7 years (3.2) 8 years (3.47), 9 years (4) and 10 years (5). Mean stages for MT group were: $1.58,2.37,2.77,3.18,3.28,3.66,3.22,4,5$ and 5 , and for TT group were: 1.3, 1.9, 2, 2.57, 2.6, 2.77, 3, 2.87, 3 and 3 for years 1-10 post-LT respectively. Mean Ishak stage progression rate was 0.2 stage U/year (0.3 stage U/year in MT, 0.2 stage $\mathrm{U} /$ year TT).
Fibrosis progression rate was not significantly different between patients requiring steroids boluses for acute cellular rejection or not. Median CPA fibrosis progression rate was $0.72 \% /$ year in those requiring steroids boluses and $0.69 \% / y e a r$ in those not treated for acute cellular rejection. Mean Ishak stage progression rate was 0.2 stage $\mathrm{U} /$ year in both groups.

\section{Factors associated with early survival overall survival} and graft survival

In the TT group three patients died within 3 months: one patient after retransplant (sepsis-2 days) and two at 1 month from sepsis and multiple organ failure. There were another four deaths: one due to non-liver related causes at 6 months, two from recurrent $\mathrm{HCV}$ disease (30 and 42 months) and one at 95 months from recurrent HCC.

In the MT group, 14 patients died: five from sepsis and multiple organ failure $(0.3,0.3,0.6,1$ and 4 months), one from graft failure ( 0.5 months), one from pulmonary hypertension (0.2 months), one from ductopenic rejection (18 months) and one from recurrent $\mathrm{HCV}$ disease (30 months). Six more patients died in the current update: three from recurrent HCV disease (36, 37 and 72 months post-LT), one from embolic stroke (56 months) and one from lung adenocarcinoma (96 months).

Overall, mortality in the randomised 103 patients favoured TT patients $(p=0.036)$ as well as the 97 currently evaluated $(p=0.025)$. However, there was no statistically significant factor associated with mortality in the multivariate analysis, and no significant difference in deaths due to HCV recurrence.

Similarly, graft survival favoured the TT arm $(p=0.019): 15$ MT and seven TT patients died, and five MT/4 TT were retransplanted, but this difference was not due to recurrent disease. 


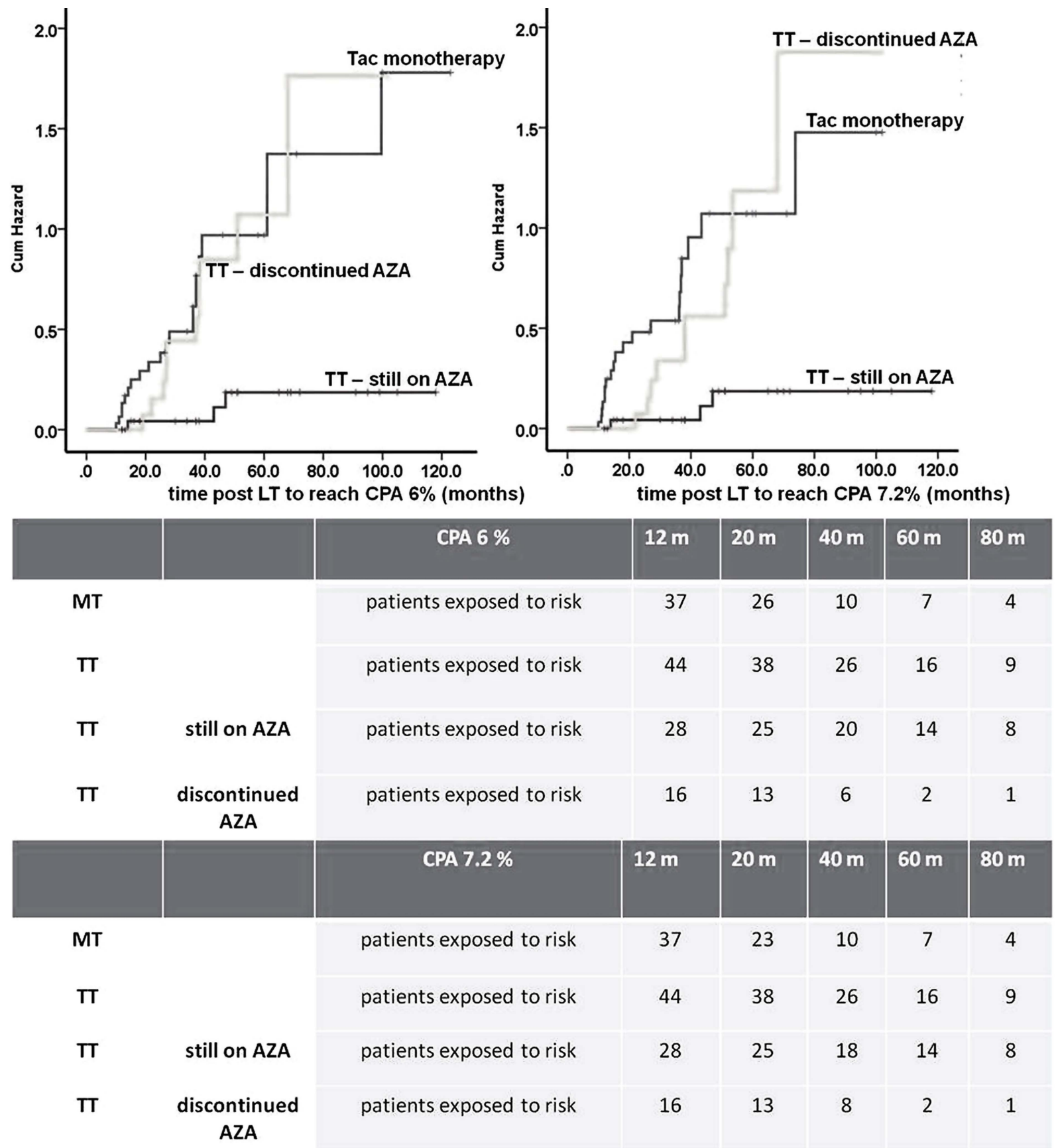

Figure 2 Hazard curves of collagen proportionate area (CPA) $6 \%$ and 7.2\%. Hazard curves of reaching CPA 6\% and 7.2\% with those achieving sustained virological response censored (18 m MT, $36 \mathrm{~m}$ TT, $36 \mathrm{~m} \mathrm{MT,} 38 \mathrm{~m} \mathrm{TT,} 40 \mathrm{~m} \mathrm{TT}, 52 \mathrm{~m} \mathrm{MT}$ ) in the two treatment arms ( $p=0.002$ for CPA $6 \%$ and $p=0.001$ for CPA $7.2 \%$ by Mantel-Cox). Sixteen patients discontinued azathioprine between 10 and 37 months post-LT. MT, monotherapy; TT, triple therapy.

\section{DISCUSSION}

In this final evaluation of our randomised study, ${ }^{1}$ the median follow-up was just over 8 years, the longest published to date following liver transplantation in a randomised trial concerning HCV cirrhosis, ${ }^{6} 18$ and given the numbers who either died within 3 years or survived more than 3 years (used for sample size calculation), this allowed a robust evaluation of clinical outcomes of recurrent HCV disease. Our outcomes included first clinical decompensation event (evaluated for the first time), HVPG and fibrosis progression defined by CPA and Ishak stage.

Fibrosis progression after liver transplantation for hepatitis $\mathrm{C}$ related cirrhosis has been studied several times ${ }^{19-24}$ mainly by assessing changes in Ishak/Metavir scores. Fibrosis progression is well recognised to have prognostic significance before ${ }^{25}$ and after transplantation. ${ }^{4}$ The overall rate of increase of disease stage described by changes in Ishak staging in our total trial population is similar or lower than fibrosis rates previously described. $^{22-24}$ The mean fibrosis Ishak stage was 1.45 and 2.1 in years 1 and 2 post-LT in our whole cohort, and 1.3 and 1.9 at years 1 and 2 post-LT respectively for the TT group, which are as low as those recently published in patients receiving sirolimus (which may have antifibrotic properties) compared with historical controls (0.62 and 1.15 metavir in year 1 and 2 biopsies, respectively). ${ }^{26}$ 


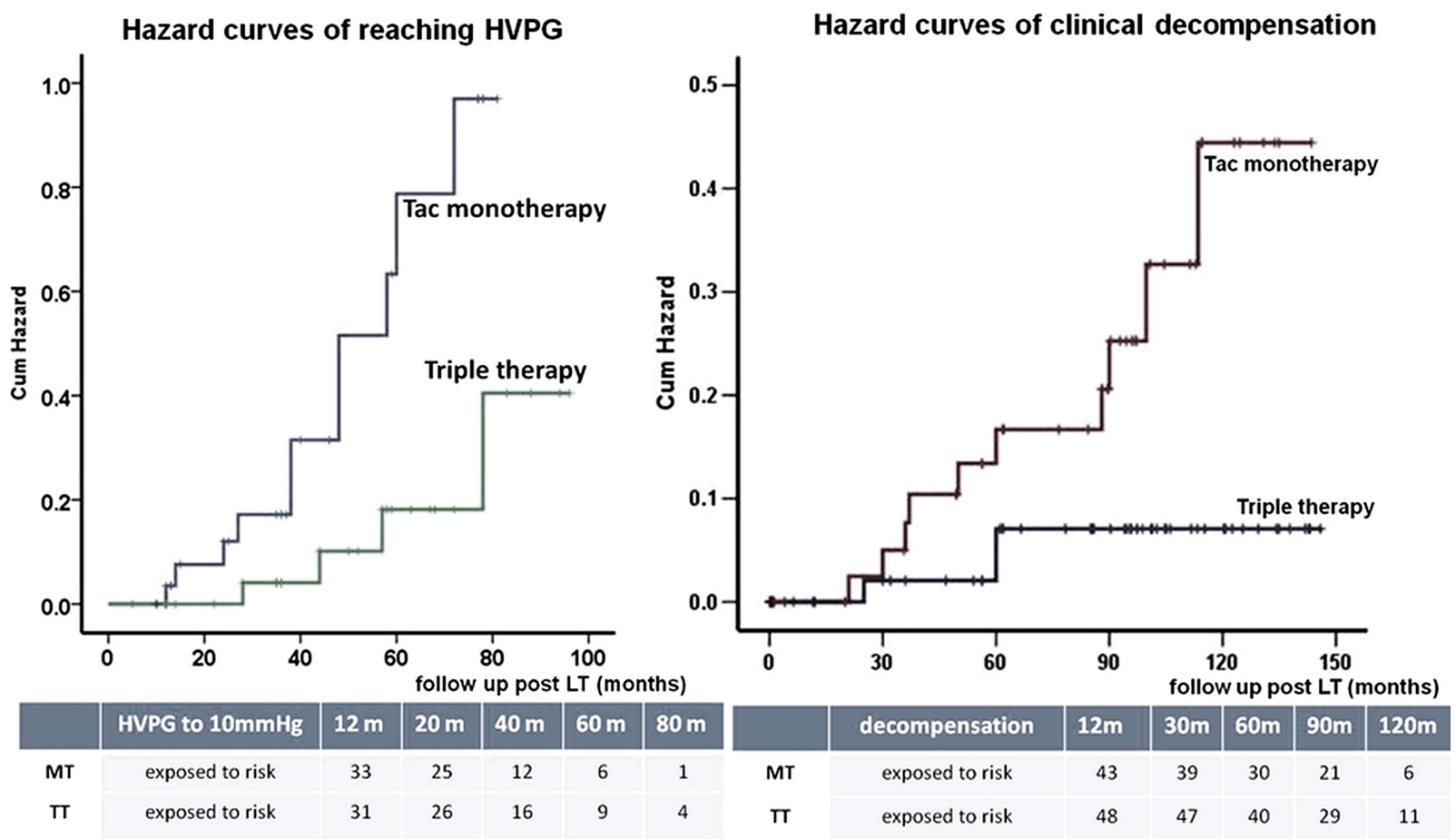

Figure 3 (A) Hazard curves of developing hepatic venous pressure gradient (HVPG) $\geq 10 \mathrm{~mm} \mathrm{Hg}$ and clinical decompensation. Hazard curves of developing HVPG $\geq 10 \mathrm{~mm} \mathrm{Hg}$ in the two treatment arms ( $p=0.019$ by Breslow) in $33 \mathrm{MT}$ and $31 \mathrm{TT}$. In all, $11 \mathrm{MT}$ reached HVPG $\geq 10 \mathrm{~mm} \mathrm{Hg}$, compared with four TT. Patients achieving sustained virological response (SVR) before reaching HVPG $\geq 10 \mathrm{~mm}$ Hg were censored at the time of SVR. (B) Hazard curves of decompensation, defined as whichever occurred first of ascites/hydrothorax, variceal bleeding or encephalopathy, in our trial cohort ( $p=0.037$ by Breslow). Decompensation occurred in 13 patients: nine MT at a mean of $70 \mathrm{~m}$ and four TT at a mean time of $91 \mathrm{~m}$. Patients achieving SVR were censored at the time of SVR. MT, monotherapy; TT, triple therapy.

The relatively low overall rate of increase of disease stage in our trial population most likely reflects use of combined therapy of tacrolimus with azathioprine and steroids and/or the generally lower trough levels of tacrolimus achieved. ${ }^{2}$ Since our first publication, we have shown that CPA assessment in $\mathrm{HCV}$ post-LT patients correlates with both Ishak stage scores and HVPG, with greater percentage changes in CPA, compared with HVPG in early portal hypertension. ${ }^{15}$ Moreover, CPA at 1 year biopsy post-LT is highly predictive of clinical outcome in HCV transplanted patients and better than Ishak stage or HVPG. ${ }^{3}$ In the current update, MT and HDNH were independently associated with reaching CPA cut-offs of $6 \% 0^{3}$ and $7.2 \%$, the latter corresponding to $\mathrm{HVPG} \geq 6 \mathrm{~mm} \mathrm{Hg},{ }^{15}$ reinforcing both the value of CPA and validating these cut-offs as endpoints. ${ }^{27}$

As in our first publication, ${ }^{1}$ outcomes favouring the TT group are supported by HVPG measurements. ${ }^{28}$ There was more clinically significant portal hypertension (associated with advent of complications and worse survival) ${ }^{29}$ in the MT group (11 patients reached $H V P G \geq 10 \mathrm{~mm} \mathrm{Hg}$, compared with four TT) corroborating the more severe fibrosis found in MT patients.

The significance of HDNH is again confirmed by us ${ }^{124}$ and others $^{30}$ as this was independently associated with Ishak stage 4, but also CPA cut-offs for decompensation and HVPG.

A limitation in this study could be the lack of evaluation of recipient IL28B polymorphism, which was also missing in the recent sirolimus study. ${ }^{26}$ Some studies suggest a higher recurrence rate of $\mathrm{HCV}$ hepatitis with the poor interferon response allele of IL28B in the recipient. ${ }^{31} 32$ However, randomisation will most likely have balanced out the more favourable polymorphism, which in any case is under represented in liver transplant populations. ${ }^{32}$ Moreover, IL28B was not significantly associated with either overall or liver related mortality in one study, ${ }^{32}$ and there has been a selection bias in most studies, as only patients with biopsies were evaluated, that is, not every patient with recurrent hepatitis $\mathrm{C}$ was biopsied. ${ }^{31}$ Moreover, no study evaluated immunosuppression when analysing severity of recurrence. $^{31-35}$ Last, some studies do not show an association of recipient IL28B with worse HCV disease recurrence. ${ }^{36}$

Our TT group received azathioprine, which many centres have substituted with mycophenalate which however may worsen fibrosis progression compared with azathioprine. ${ }^{5}$ In addition, low dose maintenance steroids may also favour less severe recurrence and improve graft survival. ${ }^{37-39}$ However, the use of steroids in transplantation for HCV cirrhosis remains an unresolved issue. ${ }^{6}$ Interestingly, although steroids boluses greatly increase HCV RNA levels, ${ }^{40}$ our TT group had more rejection episodes treated with high dose steroids, ${ }^{9}$ so it may be that the long term benefit of immune modulation with steroids is more important than the risk of HCV activation following steroid boluses for rejection. Indeed, a recent study has shown no distinct advantage of steroid avoidance ${ }^{18}$ and another group have shown that steroid-free immunosuppression leads to a higher rate of chronic rejection. ${ }^{41}$

In conclusion, long term maintenance immunosuppression with tacrolimus, azathioprine and shorter term prednisolone in HCV cirrhosis recipients resulted in a slower onset of histological severe fibrosis confirmed by Ishak stage and CPA, less portal hypertension, and less clinical decompensation compared with tacrolimus alone. Our results support and extend our initial report. ${ }^{1}$ Given that our TT arm has the lowest fibrosis progression rate published so far-lower than sirolimus $-{ }^{26}$ and that there is some evidence that azathioprine is better than 

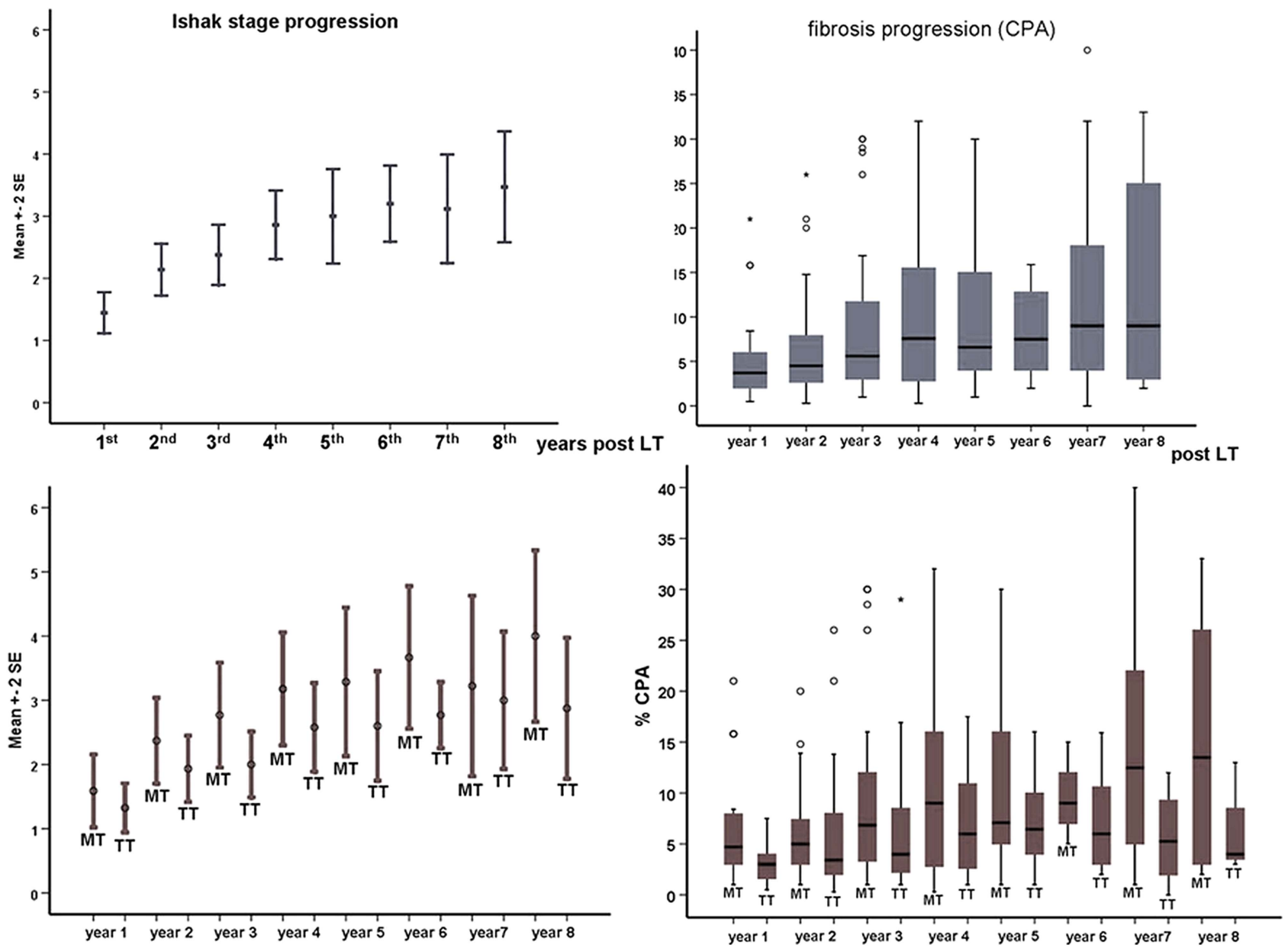

Figure 4 Fibrosis progression over time based on collagen proportionate area (CPA) and Ishak stage. Mean fibrosis according to time post-LT based on CPA and Ishak stage. Overall, 310 biopsies were evaluated in 49 MT and 48 TT: Median CPA fibrosis progression rate was 1.5\%/year. Each box plot shows the median value, the IQR and the range of CPA each year. Ishak stage progression is presented as mean values \pm 2 SD to allow comparison with work from others. MT, monotherapy; TT, triple therapy.

mycophenalate, ${ }^{5}$ our TT regimen could be considered as a first choice for patients transplanted for HCV cirrhosis, until other evidence proves otherwise.

Competing interests $\mathrm{AKB}$ and $\mathrm{APD}$ have an unrestricted educational grant from Pfizer.

Ethics approval The hospital ethics committees at each site.

Provenance and peer review Not commissioned; externally peer reviewed.

Open Access This is an Open Access article distributed in accordance with the Creative Commons Attribution Non Commercial (CC BY-NC 3.0) license, which permits others to distribute, remix, adapt, build upon this work non-commercially, and license their derivative works on different terms, provided the original work is properly cited and the use is non-commercial. See: http://creativecommons.org/ licenses/by-nc/3.0/

\section{REFERENCES}

1 Manousou P, Samonakis D, Cholongitas E, et al. Outcome of recurrent hepatitis C virus after liver transplantation in a randomized trial of tacrolimus monotherapy versus triple therapy. Liver Transp/ 2009;15:1783-91.

2 Samonakis DN, Triantos CK, Thalheimer U, et al. Immunosuppression and donor age with respect to severity of HCV recurrence after liver transplantation. Liver Transp/ 2005;11:386-95.

3 Manousou P, Dhillon AP, Isgro G, et al. Digital image analysis of liver collagen predicts clinical outcome of recurrent hepatitis $C$ virus 1 year after liver transplantation. Liver Transp/ 2011;17:178-88.

4 Manousou P, Burroughs AK, Sochatzis ET, et al. Digital image analysis of collagen assessment of progression of fibrosis in recurrent HCV after liver transplantation. J. Hepatol 2013;58:962-8.
5 Germani G, Pleguezuelo M, Villamil F, et al. Azathioprine in liver transplantation: a reevaluation of its use and a comparison with mycophenolate mofetil. Am J Transplant 2009;9:1725-31.

6 Samonakis DN, Germani G, Burroughs AK. Immunosuppression and HCV recurrence after liver transplantation. J Hepatol 2012;56:973-83.

7 Berenguer M, Royuela A, Zamora J. Immunosuppression with calcineurin inhibitors with respect to the outcome of HCV recurrence after liver transplantation: results of a meta-analysis. Liver Transp/ 2007;13:21-9.

8 Kakumu S, Takayanagi M, Iwata K, et al. Cyclosporine therapy affects aminotransferase activity but not hepatitis C virus RNA levels in chronic hepatitis C. J Gastroenterol Hepatol 1997; 12:62-6.

9 Samonakis DN, Mela M, Quaglia A, et al. Rejection rates in a randomised trial of tacrolimus monotherapy versus triple therapy in liver transplant recipients with hepatitis C virus cirrhosis. Transpl Infect Dis 2006;8:3-12.

10 Stuyver L, Rossau R, Wyseur A, et al. Typing of hepatitis C virus isolates and characterization of new subtypes using a line probe assay. J Gen Virol 1993;74(Pt 6):1093-102.

11 Young KK, Resnick RM, Myers TW. Detection of hepatitis C virus RNA by a combined reverse transcription-polymerase chain reaction assay. J Clin Microbiol 1993;31:882-6

12 Ishak K, Baptista A, Bianchi L, et al. Histological grading and staging of chronic hepatitis. J Hepatol 1995:22:696-9.

13 Cholongitas E, Quaglia A, Samonakis D, et al. Transjugular liver biopsy: how good is it for accurate histological interpretation? Gut 2006;55:1789-94.

14 Crawford AR, Lin XZ, Crawford JM. The normal adult human liver biopsy: a quantitative reference standard. Hepatology 1998;28:323-31.

15 Calvaruso V, Burroughs AK, Standish R, et al. Computer-assisted image analysis of liver collagen: relationship to Ishak scoring and hepatic venous pressure gradient. Hepatology 2009;49:1236-44.

16 Datta GS, Hudson M, Burroughs AK, et al. Grading of cellular rejection after orthotopic liver transplantation. Hepatology 1995:21:46-57. 
17 Freedman LS. Tables of the number of patients required in clinical trials using the logrank test. Stat Med 1982;1:121-9.

18 Klintmalm GB, Davis GL, Teperman L, et al. A randomized, multicenter study comparing steroid-free immunosuppression and standard immunosuppression for liver transplant recipients with chronic hepatitis C. Liver Transp/ 2011;17:1394-403.

19 Yilmaz N, Shiffman ML, Stravitz RT, et al. A prospective evaluation of fibrosis progression in patients with recurrent hepatitis $C$ virus following liver transplantation. Liver Transp/ 2007;13:975-83.

20 Samonakis DN, Cholongitas E, Thalheimer U, et al. Hepatic venous pressure gradient to assess fibrosis and its progression after liver transplantation for HCV cirrhosis. Liver Transp/ 2007;13:1305-11.

21 Gallegos-Orozco JF, Yosephy A, Noble B, et al. Natural history of post-liver transplantation hepatitis $\mathrm{C}$ : a review of factors that may influence its course. Liver Transp/ 2009;15:1872-81.

22 Berenguer M, Ferrell L, Watson J, et al. HCV-related fibrosis progression following liver transplantation: increase in recent years. J Hepatol 2000;32:673-84.

23 Neumann UP, Berg T, Bahra M, et al. Fibrosis progression after liver transplantation in patients with recurrent hepatitis C. J Hepatol 2004;41:830-6.

24 Wali M, Harrison RF, Gow PJ, et al. Advancing donor liver age and rapid fibrosis progression following transplantation for hepatitis C. Gut 2002:51:248-52.

25 Poynard T, Bedossa P, Opolon P. Natural history of liver fibrosis progression in patients with chronic hepatitis C. The OBSVIRC, METAVIR, CLINIVIR, and DOSVIRC groups. Lancet 1997;349:825-32.

26 McKenna GJ, Trotter JF, Klintmalm E, et al. Limiting hepatitis C virus progression in liver transplant recipients using sirolimus-based immunosuppression. $\mathrm{Am} \mathrm{J}$ Transplant 2011;11:2379-87.

27 Germani G, Hytiroglou P, Fotiadu A, et al. Assessment of fibrosis and cirrhosis in liver biopsies: an update. Semin Liver Dis 2011;31:82-90.

28 Burroughs AK, Groszmann R, Bosch J, et al. Assessment of therapeutic benefit of antiviral therapy in chronic hepatitis $C$ : is hepatic venous pressure gradient a better end point? Gut 2002;50:425-7.

29 Ripoll C, Groszmann R, Garcia-Tsao G, et al. Hepatic venous pressure gradient predicts clinical decompensation in patients with compensated cirrhosis. Gastroenterology 2007;133:481-8.
30 Berenguer $\mathrm{M}$, Prieto $\mathrm{M}$, San Juan $\mathrm{F}$, et al. Contribution of donor age to the recent decrease in patient survival among HCV-infected liver transplant recipients. Hepatology 2002:36:202-10.

31 Allam SR, Kruger B, Mehrotra A, et al. The association of IL28B polymorphism and graft survival in patients with hepatitis $C$ undergoing liver transplantation. PLoS ONE 2013;8:e54854.

32 Charlton MR, Thompson A, Veldt BJ, et al. Interleukin-28B polymorphisms are associated with histological recurrence and treatment response following liver transplantation in patients with hepatitis $C$ virus infection. Hepatology 2011:53:317-24

33 Duarte-Rojo A, Veldt BJ, Goldstein DD, et al. The course of posttransplant hepatitis $C$ infection: comparative impact of donor and recipient source of the favorable IL28B genotype and other variables. Transplantation 2012;94:197-203.

34 Eurich D, Boas-Knoop S, Ruehl M, et al. Relationship between the interleukin-28b gene polymorphism and the histological severity of hepatitis $C$ virus-induced graft inflammation and the response to antiviral therapy after liver transplantation. Liver Transp/ 2011;17:289-98.

35 Cisneros E, Banos I, Citores MJ, et al. Increased risk of severe hepatitis C virus recurrence after liver transplantation in patients with a T allele of IL28B rs12979860. Transplantation 2012;94:275-80.

36 Lange CM, Moradpour D, Doehring A, et al. Impact of donor and recipient IL28B rs12979860 genotypes on hepatitis C virus liver graft reinfection. J Hepatol 2011;55:322-7.

37 Berenguer M, Crippin J, Gish R, et al. A model to predict severe HCV-related disease following liver transplantation. Hepatology 2003;38:34-41.

38 Vivarelli M, Burra P, Barba GL, et al. Influence of steroids on HCV recurrence afte liver transplantation: a prospective study. J Hepatol 2007;47:793-8.

39 Brillanti S, Vivarelli M, De Ruvo N, et al. Slowly tapering off steroids protects the graft against hepatitis $C$ recurrence after liver transplantation. Liver Transp/ 2002:8:884-8.

40 Gane EJ, Naoumov NV, Qian KP, et al. A longitudinal analysis of hepatitis C virus replication following liver transplantation. Gastroenterology 1996;110:167-77.

41 Weiler N, Thrun I, Hoppe-Lotichius M, et al. Early steroid-free immunosuppression with FK506 after liver transplantation: long-term results of a prospectively randomized double-blinded trial. Transplantation 2010;90:1562-6. 